\title{
The relevance of affiliative relationships in horses: review and future directions
}

\author{
Helena Costa, Sara Fragoso, Filipa Heitor*
}

\section{Abstract}

For many years, studies on horse social behaviour focused mainly on social organization, dominance and aggression. There are comparatively fewer studies on affiliative relationships among horses, despite their impact on the stability of social groups, reproductive success and welfare. We believe that it is important to gain a more complete understanding of this dimension of horse social behaviour and to identify areas of research which need to be addressed in more detail.

This review summarizes the existing body of scientific knowledge on affiliative relationships among horses. Studies were conducted on a large variety of horse populations and environmental conditions, from feral to domestic horses under different management conditions. Moreover, studies conducted to date used different methodologies for data collection and analysis which make meaningful comparisons of their results more difficult. We present their main findings concerning the importance of affiliative relationships for horses and the individual and social factors associated with these relationships. Furthermore, we discuss the implications of these findings for management of domestic horses and propose avenues for future studies. We hope this review stimulates further research in this area and may contribute scientific knowledge to improve husbandry practices and horse welfare.

Pet Behaviour Science | 2019, Vol.8, 11 - 26

DOI: 10.21071/pbs.v0i8.11463

Helena Costa, Sara Fragoso, Filipa Heitor

Centro para o Conhecimento Paper review

Animal

*Avenida dos Bombeiros

Voluntários de Algés, 40A, 1495-

*Email: heitor.filipa@gmail.com

020 Algés

Telephone: +351919129548

Portugal
Keywords:

affiliative relationships; horses; management; social behaviour; welfare

\section{Highlights}

- Many studies on horse social behaviour focused on social organization, dominance and aggression, but studies on affiliative relationships are fewer and further research is still needed.

- Affiliative relationships are a social need and they contribute to the stability of social groups, reproductive success and welfare of horses.

- Studies on affiliative relationships were conducted on domestic and feral horse populations, on a wide variety of ecological and management conditions, and used different data collection and analysis methods, which make comparisons between studies more difficult. 
- This review summarizes the main findings concerning the importance of affiliative relationships for horses and the individual and social factors associated with these relationships.

- We discuss how the scientific knowledge obtained may contribute to improve husbandry practices and welfare of domestic horses and propose avenues for future research.

\section{INTRODUCTION}

Early studies on horse social behaviour focused mainly on social organization as well as dominance relationships and aggression. There is an extensive body of literature concerning social organization (e.g. Klingel 1975; Feist and McCullough 1976; Berger 1986; Feh 1999; Linklater et al. 1999), dominance relationships and agonistic behaviours in both feral and domestic horses, as well as their implications for management and housing (e.g. Clutton-Brock et al. 1976; Houpt et al. 1978; Houpt and Keiper 1982; Rutberg and Greenberg 1990; van Dierendonck et al. 1995; Weeks et al. 2000; Heitor et al. 2006a). Affiliative relationships were not as thoroughly addressed, despite their importance for the cohesion and stability of horse social groups, management and welfare. Therefore, we believe that affiliative relationships among horses deserve further study.

Studies on affiliative relationships conducted to date were performed on different horse breeds and populations, as well as on a large variety of environments and management conditions. These studies used a large variety of data collection and data analysis methods which hinders comparisons between their results and makes it more difficult to extract meaningful information. We believe that comparing the main findings of these research studies would allow us to obtain further information on the adaptive value of affiliative behaviours, the influence of environmental and management conditions on affiliative relationships and the factors that affect their development. The knowledge obtained would be very useful in guiding future research and supporting horse management decisions.
The present review intends to summarize and compare the main findings of studies conducted to date on affiliative relationships among feral and domestic horses. We also aim to discuss the implications of these findings for husbandry practices in order to improve the welfare of domestic horses. Finally, we identify gaps in knowledge and propose avenues for future research.

\section{METHODS}

Data collection was done in August 2017. We compiled scientific papers by searching for publications on affiliative behaviour in horses using the Google Scholar search engine with combinations of the following keywords: affiliative, behaviour, conflict, Equus caballus, grooming, group, horses, play, relationships and social. Papers of empirical or observational research specific to the intended topic and published in peer-reviewed english-language journals were included. We also searched the reference list of papers to identify studies that were missed in the initial search.

\section{DIVERSITY OF SUBJECTS AND METHODOLOGY IN STUDIES ON AFFILIATIVE BEHAVIOUR}

Studies on affiliative relationships were conducted on different horse populations (Equus ferus caballus) and Przewalski horse (Equus ferus przewalskii) (Kolter and Zimmermann 1988; Keiper 1988; Klimov 1988). The horses lived within a diverse range of environmental and social conditions, from feral populations with minimal human intervention (Wells and von Goldschmidt-Rothschild 1979; Kimura 1998; Cameron et al. 2009) to managed populations in captivity (Kolter and Zimmermann 1988; Keiper 1988; van Dierendonck et al. 1995; Weeks et al. 2000). Therefore, studies focused on feral and semi-feral horse populations composed of naturally formed groups with occasional introductions and removals of horses, as well as artificially formed groups of domestic horses where group composition was completely determined by humans. Some horses had been together for many months or years (van Dierendonck 1995; Weeks et al. 2000; Heitor et al. 2006b; Heitor and Vicente 2010), while other groups had been formed shortly before the study (Araba and Crowell-Davis 1994; Bourjade et al. 
2008).

In some studies, stallions were permanent members in breeding groups (Kimura 1998; Cameron et al. 2009; Bouskila et al. 2015), while in others, stallions were present only during the reproductive season (Heitor et al. 2006b; Heitor and Vicente 2010). In some cases, stallions were absent (Clutton-Brock et al. 1976; van Dierendonck et al. 1995; Weeks et al. 2000; Sigurjónsdóttir et al. 2003; van Dierendonck et al. 2004) or existed in very low numbers due to the removal of colts (Tyler 1972). Sometimes foals were weaned and removed from the group to prevent inbreeding, usually before 1-year old, either both sexes (Araba and Crowell-Davis 1994; Weeks et al. 2000; Heitor et al. 2006b; Heitor and Vicente 2010) or only males (Kimura 1998). In other cases, foals remained in the group and yearlings as well as two-year-olds were present (Wells and von Goldschmidt-Rothschild 1979; Crowell-Davis et al. 1986; van Dierendonck et al. 1995; Sigurjónsdóttir et al. 2003; van Dierendonck et al. 2004).

Most authors evaluated affiliative relationships through a combination of measures of spatial association and affiliative interactions (e.g. van Dierendonck et al. 1995; Kimura 1998; Sigurjónsdóttir et al. 2003; van Dierendonck et al. 2004; Heitor et al. 2006b; Cameron et al. 2009; Heitor and Vicente 2010). Nevertheless, some studies used only spatial association measures (Weeks et al. 2000; Bouskila et al. 2015). Proximity was based on the nearest neighbour (Wells and von GoldschmidtRothschild 1979; Arnold and Grassia 1982; CrowellDavis et al. 1986; Kimura 1998; Heitor et al. 2006b; Heitor and Vicente 2010) or associates, i.e. horses within a given distance of the focal animal (Araba and Crowell-Davis 1994; van Dierendonck et al. 1995; Weeks et al. 2000; Sigurjónsdóttir et al. 2003; Heitor et al. 2006b; Cameron et al. 2009; Heitor and Vicente 2010). Most commonly, associates were defined as being within two body-lengths of each other, which is purported to correspond to to a horse's personal space (van Dierendonck et al. 1995; Sigurjónsdóttir et al. 2003; van Dierendonck et al. 2004; Cameron et al. 2009; Bouskila et al. 2015). Some authors recorded only affiliative interactions related to mutual grooming and play (Clutton-Brock et al. 1976; Crowell-Davis et al. 1986; Araba and Crowell-Davis 1994; van Dierendonck et al. 1995; Kimura 1998; Sigurjónsdóttir et al. 2003; van
Dierendonck et al. 2004; Rho et al. 2007). Other studies also included approaches, follows or friendly contacts (Wells and von Goldschmidt-Rothschild 1979; Arnold and Grassia 1982; Heitor et al. 2006b; Cameron et al. 2009; Heitor and Vicente 2010). When assessing the relationship between affiliative relationships and dominance rank, criteria for assessing dyadic dominance relationships was similar between studies, but the methods for constructing the dominance hierarchy and assigning ranks was not always the same. When studying factors related to affiliative relationships, many authors used simple correlations or two-sample tests (e.g. Clutton-Brock et al. 1976; Crowell-Davis et al. 1986; Araba and Crowell-Davis 1994; Weeks et al. 2000; Rho et al. 2007), while others used also matrix correlation tests (e.g. van Dierendonck et al. 1995; Sigurjónsdóttir et al. 2003; van Dierendonck et al. 2004; Heitor et al. 2006b; Heitor and Vicente 2010), Cluster Analysis (Wells and von GoldschmidtRothschild 1979; Kimura 1998), Principal Components Analysis (Arnold and Grassia 1982; van Dierendonck et al. 2004), Generalized Linear Models (Cameron et al. 2009) or Social Network Analysis (Bouskila et al. 2015).

Given the diversity of environmental and management conditions of horse populations studied to date and the diversity of methods applied, comparisons between studies can only provide suggestive evidence of important variables and associations, which must be later confirmed by experimental studies. Bearing this in mind, we present the differences as well as the similarities in the findings of those studies and point out the most relevant patterns that emerged from our analysis.

\section{THE IMPORTANCE OF AFFILIATIVE RELATIONSHIPS}

Horses are social animals. The basic reproductive unit of feral horses is the band, a stable group composed of several mares, their offspring and one or more stallions that defend the mares from other males year round, as is typical of female defense polygyny (Salter and Hudson 1982; Kaseda et al. 1995; Linklater et al. 1999; Linklater 2000). Several hypotheses have been formulated to explain the existence of single-stallion bands and multiple stallion bands. Feh (1999) found evidence of cooperation among stallions in bands with 
multiple stallions. Linklater and Cameron (2000) rejected cooperative hypotheses and proposed mate parasitism and consort hypotheses as better alternative explanations.

Young males and females usually leave their natal bands upon reaching sexual maturity (2-3 years old) and form new groups or join existing ones (Klingel 1975; Salter and Hudson 1982; Berger 1986; Feh 1999) to prevent inbreeding (Monard and Duncan 1996; Monard et al. 1996). Females join other bands directly, but males integrate bachelor groups for a few years where they develop social skills which are necessary to maintain a band (Hoffmann 1985; McDonnell and Haviland 1995; Khalil and Kaseda 1998). Despite frequent changes in composition within bachelor groups, some long-term associations among males can be developed (Salter and Hudson 1982).

\section{The adaptive value of affiliative relationships}

Horses tend to form stable affiliative relationships in feral and domestic horse groups that include adult mares (e.g. stability over a 3-year period: Tyler 1972; van Dierendonck et al. 2004; Heitor and Vicente 2010), but unstable bonds that suffer seasonal changes have also been observed (Kimura 1998). Stable relationships within bands enhance female reproductive success by reducing stallion harassment and inter-mare aggression associated with band change and male takeovers (Berger 1983; Kaseda et al. 1995; Linklater et al. 1999). Long-term bonds between stallions and mares may also improve oestrus detection by stallions (Duncan 1980; Salter and Hudson 1982). In addition, Cameron et al. (2009) reported that mares with stable group membership that contributed more for social bonding had higher reproductive success.

Affiliative relationships among horses are expressed by spending time in proximity and participating in affiliative interactions, such as mutual grooming and social play (Tyler 1972; Wells and von GoldschmidtRothschild 1979; Arnold and Grassia 1982; Kimura 1998; Sigurjónsdóttir et al. 2003; van Dierendonck and Spruijt 2012). Horses usually have one or more preferred partners for affiliative relationships (Tyler 1972; Arnold and Grassia 1982; Estep et al. 1993; van Dierendonck et al. 1995; Kimura 1998; Sigurjónsdóttir et al. 2003; van Dierendonck et al. 2004; Bouskila et al. 2015). Some horses are more popular than others, as measured by the number of group members that have them as a preferred partner (Sigurjónsdóttir et al. 2003). Preferred partners for mutual grooming tend to be the same as preferred partners for proximity (CluttonBrock et al. 1976; Sigurjónsdóttir et al. 2003; van Dierendonck et al. 2004; Heitor et al. 2006b), but sometimes these partnerships differ (Kimura 1998; Gilbert-Norton et al. 2004). These findings suggest that, although proximity and mutual grooming are both related to bonds in horses, their functions may be slightly different.

Maintaining affiliative relationships with particular partners within the group is important for horses, both in bands and bachelor groups, as shown by interventions in social interactions of group members (Heitor et al. 2006a; van Dierendonck et al. 2009; Granquist et al. 2012; Schneider and Krueger 2012; Krueger et al. 2015). Interventions in agonistic behaviours seemed to promote group cohesion and to prevent social disruption in a bachelor group of Przewalski horses (Krueger et al. 2015). Interventions in affiliative interactions seemed to function as a means to prevent a potential weakening of a horse's own bonds with preferred partners (van Dierendonck et al. 2009, Schneider and Krueger 2012). In addition, there is some preliminary evidence that affiliative interactions exchanged between horses after a conflict could function as reconciliation behaviours, thereby preventing further aggression and maintain the affiliative relationship between former opponents (Cozzi et al. 2010).

It has been suggested that affiliative relationships may provide other indirect benefits to mares by reducing aggression received (Cameron et al. 2009). Aggression increases stress levels and decreases body condition, thereby reducing reproductive success (Linklater et al. 1999). Nevertheless, frequency of agonistic interactions is not always lower among preferred partners, both among adults (Clutton-Brock et al. 1976; Weeks et al. 2000; Heitor et al. 2006b) and among foals (Araba and Crowell-Davis 1994). 


\section{Benefits associated with affiliative interactions}

There are benefits associated with performing affiliative interactions, such as mutual grooming and play. Mutual grooming enables horses to obtain care of the coat in areas of the body difficult for them to reach (Tyler 1972), promotes appeasement (Feist and McCullough 1976) and reduces social tension (Feh and de Mazières 1993). This behaviour is performed by horses of all sex-age classes but its frequency varies greatly (Clutton-Brock et al. 1976; Keiper 1988; Heitor et al. 2006b). In some groups mutual grooming was relatively frequent (Sigurjónsdóttir et al. 2003; van Dierendonck et al. 2004), but in other groups the frequency was low and some horses were never observed participating in it (Wells and von Goldschmidt-Rothschild 1979; Arnold and Grassia 1982; Crowell-Davis et al. 1986; Heitor et al. 2006b; Heitor and Vicente 2010). Mutual grooming frequencies vary seasonally, with higher frequencies during spring and summer due to coat shedding and higher density of tabanid flies (Tyler 1972; Wells and von Goldschmidt-Rothschild 1979), which could partly account for the variation in study results. Play behaviour in horses was described by McDonnell and Poulin (2002) and it is generally believed to improve motor, cognitive and social skills (Bekoff and Allen 1998). Social play is mainly performed by younger horses and males but it is rarely seen in adult mares (Tyler 1972; Wells and von Goldschmidt-Rothschild 1979; Sigurjónsdóttir et al. 2003; Zharkikh and Andersen 2009).

Van Dierendonck and Spruijt (2012) argued that mutual grooming and play could be considered "ethological needs" because these behaviours are performed by all individuals, self-rewarding, have a rebound effect and chronic stress is induced in absence of a social partner. In addition, van Dierendonck and Spruijt (2012) reviewed evidence that horses that are deprived from social contact with other horses can suffer chronic stress and engage in abnormal behaviours such as stereotypies. For example, van Dierendonck (2006) observed that horses housed in a social-contact-at-adistance system conspicuously anticipated opportunities for direct physical contact with other horses and showed stress reactions when social contact was no longer allowed. Consistent with these findings,
Visser et al. (2008) observed that stress-related behaviours and stereotypies were displayed more frequently in individually housed horses than in horses kept in pairs. In addition, Hartmann et al. (2012) reviewed evidence that the opportunity for social contact is related to improved development of social skills, decreased reactivity and decreased aggression in domestic horses. Housing young horses singly does not give them the opportunity to practice their social skills, so they are more prone to injuries when interacting with other horses as adults (Søndergaard and Christensen 2007).

In sum, affiliative relationships promote group stability, which is related to increased reproductive success in feral horses. Moreover, the opportunity to engage in affiliative interactions is an ethological need for horses and it is necessary for normal development of their social skills.

\section{FACTORS ASSOCIATED WITH AFFILIATIVE RELATIONSHIPS}

Although the importance of affiliative relationships for horses is undeniable, factors that determine the strength of affiliative relationships and choice of preferred partners are less clear. We found contradicting results between studies, which could be due to the differences in horse breeds, management conditions, data collection and data analysis methods of studies conducted to date. We present the main findings of studies that assessed the association between affiliative relationships and the factors age, gender, dominance, kinship and familiarity, reproductive state and social environment.

Age

Many authors observed that horses formed stronger bonds with other horses of similar age, especially within their age class (e.g. foals, subadults, adults). This could be due to their similar environmental and social needs. When integrating new bands after natal dispersal, young females usually had one particular subadult female as preferred partner for proximity and affiliative interactions, which was close in age (Monard and Duncan 1996). In groups without mature stallions, horses more often performed affiliative interactions 
(mutual grooming and play) and maintained proximity with horses of similar age (Clutton-Brock et al. 1976; Sigurjónsdóttir et al. 2003). In a Camargue horse herd with a mature stallion, Wells and von GoldschmidtRothschild (1979) also observed that, excluding close kin relationships via the mother, horses spent more time in proximity to other horses of similar age. In foals, mutual grooming was most common with other foals (Crowell-Davis et al. 1986; Rho et al. 2007). In addition, when mothers and close relatives were excluded, foals were more often nearest neighbours with other foals (Crowell-Davis et al. 1986) or partners for affiliative interactions (Wells and von GoldschmidtRothschild 1979). Nevertheless, some exceptions were found: age similarity was not related to affiliative relationships among adult Sorraia mares (Heitor et al. 2006b) and Konik horses (Bouskila et al. 2015).

Studies show that foals and subadults take part in affiliative interactions more frequently than adults, particularly social play (Tyler 1972; Feist and McCullough 1976; Wells and von GoldschmidtRothschild 1979; Sigurjónsdóttir et al. 2003; Zharkikh and Andersen 2009) and mutual grooming (Keiper 1988; Granquist et al. 2012). Among adult horses, age seems less important, as it was not associated with frequency of mutual grooming in Highland pony mares (Clutton-Brock et al. 1976) or frequency of affiliative interactions in bachelor Przewalski males (Zharkikh and Andersen 2009). Subadults had more preferred partners for mutual grooming than adult mares in harems (Granquist et al. 2012). However, the strength of affiliative relationships and diversity of partners was not related to age in adult Sorraia mares (Heitor and Vicente 2010). Consistent with these findings, the number of preferred partners for affiliative interactions (mutual grooming and play) and popularity as a partner were not related to age in Icelandic horses (Sigurjónsdóttir et al. 2003). Therefore, studies in horses have not shown a decline in sociability with aging such as referred in humans and nonhuman primates (Pavelka 1991; Veenema et al. 1997). Nevertheless, the effects of aging on affiliative relationships would be best examined by longitudinal studies to allow the control of confounding variables. We do not know of any longitudinal study conducted to date that has investigated the changes in affiliative relationships of horses as they age.

\section{Gender}

Icelandic horses spent more time in proximity and groomed more often with horses of the same sex (Sigurjónsdóttir et al. 2003). Araba and Crowell-Davis (1994) observed that foals associated more often with foals of the same sex than with foals of the opposite sex, both before and after weaning. Nevertheless, Weeks et al. (2000) reported that the most common spatial associate of foals was not related to gender either before or after weaning. Crowell-Davis et al. (1986) found that male foals groomed almost exclusively with female foals, fillies groomed other foals irrespective of gender but they were more likely to have other fillies as nearest neighbours. Foals were as likely to mutual groom with a foal of the opposite sex as with a foal of the same sex in Jeju ponies (Rho et al. 2007). Young males preferred to play within their own sex-age class, while the subadult females played with both sexes (Sigurjónsdóttir et al. 20003). Monard et al. (1996) reported that before natal dispersal, young Camargue mares played more often with other immatures of both sexes. Therefore, it seems that young males tend to mutual groom more often with opposite sex partners and more often play with same-sex partners, while females do not display gender-related differences. Female foals took part in mutual grooming more often than male foals in Welsh ponies (CrowellDavis et al. 1986). Young males played more often than females (Wells and von Goldschmidt-Rothschild 1979; Sigurjónsdóttir et al. 2003), and they also had more playing partners and were more popular as play partners than females (Sigurjónsdóttir et al. 2003).

These differences between genders may reflect different functional benefits of affiliative relationships for stallions and mares. For mares, affiliative relationships established with both the band stallion and other mares contribute to stable group membership which increases reproductive success (Linklater et al. 1999). For males, bonding with other stallions may be less important because bachelor bands are unstable and the greatest reproductive success is achieved through relationships established with mares in a band (Linklater et al. 1999). Nevertheless, social play may be more frequent in males than females because a male's play-fighting experiences at an early age could help develop skills which will be important for stallions in acquiring, 
maintaining and defending a harem from other males (Rho et al. 2007). Further study is necessary to assess whether mutual grooming and social play at an early age affect the strength of affiliative relationships and reproductive success later in life.

\section{Dominance}

Relatively stable and linear dominance hierarchies based mainly on age, are usually developed within horse social groups (e.g. Clutton-Brock et al. 1976; Wells and von Goldschmidt-Rothschild 1979; van Dierendonck et al. 1995; Sigurjónsdóttir et al. 2003; Gilbert-Norton et al. 2004; Heitor et al. 2006a), although Feist and McCullough (1976) found no consistent dominance hierarchy among mares in feral harem groups.

Contribution to affiliative relationships may be related to dominance relationships within each pair of horses. The dominant individual within each pair of horses has been reported to initiate affiliative interactions more frequently than the subordinate (Clutton-Brock et al. 1976; Wells and von Goldschmidt-Rothschild 1979; Heitor et al. 2010). However, Tyler (1972) noted that mutual grooming bouts were most often initiated by subordinates (Tyler 1972). Subordinates may be inhibited from initiating affiliative interactions with dominants (Wells and von Goldschmidt-Rothschild 1979) due to the increased probability of receiving agonistic interactions from them (Heitor et al. 2006a). Moreover, subordinates may leave dominants due to agonistic interactions received from them, thereby contributing less to proximity (Heitor and Vicente 2010).

Some studies found that horses with similar dominance rank developed stronger affiliative relationships (Clutton-Brock et al. 1976; Wells and von GoldschmidtRothschild 1979; Kimura 1998; Sigurjónsdóttir et al. 2003), spent more time in proximity (van Dierendonck et al. 1995; Kimura 1998; Heitor et al. 2006b) or groomed more often (Clutton-Brock et al. 1976; Sigurjónsdóttir et al. 2003). However, other studies did not find relationships between mutual grooming and rank distance (van Dierendonck et al. 1995; van Dierendonck et al. 2004; Heitor et al. 2006b) or between proximity and rank distance (van Dierendonck et al.
2004; Bouskila et al. 2015).

Mutual grooming frequency was not related to rank in free-ranging Highland ponies (Clutton-Brock et al. 1976). Nevertheless, lower-ranking Przewalski horses in captivity were involved in mutual grooming significantly more often (Keiper 1988). Popularity as a partner for mutual grooming or play was not related to rank in Icelandic horses (Sigurjónsdóttir et al. 2003). In addition, rank was not related to sociability (based on the number of spatial associates) in mares and foals (Weeks et al. 2000) or to the number of play bouts initiated or terminated by foals (Araba and CrowellDavis 1994).

In sum, affiliative relationships may be influenced by dyadic dominance relationships and rank similarity, but dominance rank seems less important.

\section{Kinship and familiarity}

In feral horses' natal bands, females bond more strongly with their mother and siblings (Tyler 1972; Wells and von Goldschmidt-Rothschild 1979; Monard et al. 1996). These bonds are usually broken at the time of natal dispersal (Klingel 1975; Salter and Hudson 1982; Waring 1983; Berger 1986; Feh 1999) but longterm bonds may develop among adult matrilineal relatives if they ever meet again (Tyler 1972; Monard and Duncan 1996). Some authors found that mares who were close relatives via the mother spent more time in proximity (Gilbert-Norton et al. 2004) or participated in mutual grooming more often (Keiper 1988; Sigurjónsdóttir et al. 2003; van Dierendonck et al. 2004; Heitor et al. 2006b). By contrast, other studies found no relationship between mutual grooming and kinship via the mother (Clutton-Brock et al. 1976; van Dierendonck et al. 1995). Moreover, affiliative relationships were not stronger between close relatives in Sorraia mares (Heitor et al. 2006b; Heitor and Vicente 2010) or Icelandic horses of all age-sex classes without intact stallions (van Dierendonck et al. 1995).

In herds where all horses were familiar to each other, affiliative relationships were sometimes related to kinship beyond close relatives via the mother, as measured by the degree of genetic relatedness (Sigurjónsdóttir et al. 2003; van Dierendonck et al. 2004; 
Heitor et al. 2006b). Nevertheless, the relationship between kinship and affiliative relationships among mares reported by Heitor et al. (2006b) was no longer significant in later years (Heitor and Vicente 2010). Moreover, Bouskila et al. (2015) found no significant relationship between genetic relatedness and strength of spatial associations in semi-feral Konik horses.

Monard and Duncan (1996) reported that young dispersing females more often joined bands with familiar subadult females that had previously belonged to their maternal groups and they formed close affiliative relationships with them, at least initially. However, in their study, familiar females were often close relatives, so it was not possible to separate the familiarity and kinship effects. Arnold and Grassia (1982) observed that mares that had been in the same group before the study spent more time close to each other when resting. In Icelandic horses, the relationship between frequency of mutual grooming and kinship was not significant when familiarity was controlled for (van Dierendonck et al. 2004). Van Dierendonck et al. (2004) stated that, when unfamiliar animals were introduced into the group, familiarity was a more powerful predictor of the frequency of mutual grooming than kinship.

These findings suggest that horses may be able to recognize close kin via the mother and may also be able to discriminate genetic relatedness to a certain extent, although these abilities need to be tested experimentally. Affiliative relationships with kin seem more important in natal bands between motheroffspring and siblings than among adults. Familiarity with another horse seems to have greater influence on affiliative relationships when animals move to new groups where most other horses are unfamiliar to them. We suggest that selective pressure for developing affiliative relationships based on kin and familiarity may be low in horses because they are unlikely to find close relatives and familiar individuals in their new groups after natal dispersal.

\section{Reproductive state}

Foaling leads to changes in affiliative relationships among mares (Estep et al. 1993; van Dierendonck et al. 2004; Heitor and Vicente 2010). The distance of new mothers to other group members increased after foaling (Tyler 1972; Klimov 1988; Estep et al. 1993; van Dierendonck et al. 2004; Heitor and Vicente 2010). Mothers seemed to be mainly responsible for this because they did not receive lower frequency of affiliative interactions (Heitor and Vicente 2010) but they initiated affiliative interactions less often and contributed less to proximity with group members after foaling (Estep et al. 1993; Heitor and Vicente 2010). Estep et al. (1993) also observed that preferred partners for proximity changed after foal birth. Mares spent more time in proximity to others in the same reproductive state, so barren mares and mares with foals were spatially separated into sub-groups (Arnold and Grassia 1982; van Dierendonck et al. 2004; Heitor and Vicente 2010; Bouskila et al. 2015).

Despite changes in spatial proximity, patterns of affiliative interactions suggest that affiliative relationships among mares before foaling are not broken and replaced by new relationships with mares in the same reproductive state. In Icelandic horses, mares groomed more often with others in the same reproductive state but they maintained their preferred mutual grooming partners (van Dierendonck et al. 2004). In Sorraia horses, mares did not engage in affiliative interactions more frequently with others in the same reproductive state (Heitor and Vicente 2010).

Social isolation after parturition is important for imprinting and individual recognition between dam and foal, preventing foals from bonding with other horses in the first few days after birth (Estep et al. 1993; van Dierendonck et al. 2004). The sub-grouping of dams and foals may facilitate protection of those foals from interactions with other group members (van Dierendonck et al. 2004). In addition, mutual attraction between mares with foals may be a by-product of mutual attraction between foals (van Dierendonck et al. 2004). As foals begin to interact with each other and their dams maintain proximity to them, mares in the same reproductive state may end up spending more time in proximity.

\section{Social environment}

Sigurjónsdóttir et al. (2003) noticed that mutual grooming seemed to be more common in groups 
without stallions. In addition, in these groups mares more often groomed with other mares of similar age (Tyler 1972; Clutton-Brock et al. 1976; Sigurjónsdóttir et al. 2003) while mares in harems engaged in affiliative interactions more frequently with their 0-3 year old offspring but rarely with other mares (Wells and von Goldschmidt-Rothschild 1979). Granquist et al. (2012) observed that in stable groups with a stallion, mares showed less developed dominance hierarchies, lower frequencies of aggression, fewer preferred mutual grooming partners and made fewer interventions in affiliative interactions of group members than in groups without stallions. The overall mutual grooming frequency was similar in harems and non-stallion groups. Granquist et al. (2012) suggested that the presence of stallions and their herding movements to maintain cohesiveness of the group may reduce the need or opportunity for interactions among mares (Granquist et al. 2012). Moreover, Sigurjónsdóttir et al. (2003) suggested that affiliative relationships could be dependent on the dominance status of the stallion and that the social structure of groups without a stallion could be similar to that of harems with a low-ranking stallion. Affiliative relationships among mares were also deeply affected by stallion behaviour in a group of Przewalski horses in captivity: the stallion directed intense aggression towards some of the mares and herded other mares away, causing splitting of the group (Kolter and Zimmermann 1988).

Mares affect the choice of preferred partners of their offspring before weaning and also to some extent after weaning, although less significantly so. Foals and yearlings associate more with the offspring of their dam's preferred spatial associate (Wells and von Goldschmidt-Rothschild 1979; Araba and CrowellDavis 1994; Weeks et al. 2000). Nevertheless, the stability of this influence in the long term was not yet addressed. Heitor and Vicente (2008) reported that rank and maternal experience of mares had little influence on the development of affiliative relationships of their foals with other horses. Sociability rates based on the number of spatial associates were significantly correlated in dams and their foals prior to weaning, but not after weaning (Weeks et al. 2000).

The presence of adults beyond the mother and the adult-young ratio are important for social development of young horses. Bourjade et al. (2008) found that when adults were present in same-sex groups, young horses between 1-2 years old had clear preferred partners, displayed new behaviour patterns and showed decreased aggression, compared with same-sex groups without adults. In groups with lower adult-young ratio, young Przewalski horses between 1-2 years old spent more time in association with other young horses, segregated more from adults and were more aggressive than in higher adult-young ratio groups (Bourjade et al. 2009). Nevertheless, the frequency of affiliative interactions and number of preferred spatial partners was not related to the adult-young ratio (Bourjade et al. 2009). Because dams and other adults can be important learning models for young horses (Bourjade et al. 2009), more studies are needed to address the consequences of management procedures such as weaning and keeping weaned young horses in same-age groups on the development of social skills and affiliative relationships in horses.

\section{IMPLICATIONS FOR HUSBANDRY PRACTICES AND WELFARE}

Broom (1986) defined welfare as the state of an animal with regards to its attempts to cope with its environment. Domestic horses do not have control over some features of their environment (e.g. home range, group members and mating partners). Therefore, understanding the ethological needs of horses regarding affiliative behaviour and relationships may provide valuable information to improve husbandry practices and horse welfare. Domestication caused changes in horse behaviour, especially decreased fear and reactivity, but did not significantly affect social behaviour (van Dierendonck and Spruijt 2012). As stated by these authors, engaging in affiliative interactions such as mutual grooming and social play is an ethological need.

Although husbandry conditions have improved over the last decades, many domestic horses are still housed individually in enclosed stables with limited space available, most of them in boxes (Hartmann et al. 2012). Physical contact with other horses is typically limited, especially among mature stallions (Hartmann et al. 2012). Because they are deprived of social contact, most affiliative behaviours cannot be performed. In addition, 
whereas horses kept at pasture tend to associate with preferred group members and distance themselves from others, social relationships with a stabled horse's closest neighbours are not often taken into account when deciding on housing arrangements (Redgate and Davidson 2007). In other cases, horses are (semi-)permanently housed in large groups. Confined spaces where animals cannot avoid dominant individuals and aggressive behaviours may result in more defined dominance hierarchies, increased competition for resources or higher aggression rates (Houpt and Keiper 1982; Keiper 1986; Mills and Nankervis 1999; Price 1999; Andersen et al. 2006). In addition, in managed horse herds where group composition is frequently determined or changed by man, bonds may not develop or be disrupted (Tyler 1972) and relationships need to be readjusted periodically, which may cause increased aggression (Waring 1983).

Based on the main findings of this review, we propose some recommendations regarding management and husbandry of domestic horses in order to improve their welfare.

\section{Individual versus group housing}

The findings of this review concerning the importance of affiliative relationships provide a strong basis for recommending the use of housing conditions where horses are allowed permanent social contact and development of affiliative relationships. Horses should be kept as a group at pasture or with access to an outdoor paddock. The enclosure area will depend on group size, but it should provide them ample space to move away from other horses if needed. This is important, for example, for new mothers to create some distance between their newborn foal and other group members.

\section{Group composition}

Horses tend to form stronger bonds with others of similar age, especially among young horses. Moreover, young horses get frequently involved in affiliative interactions with partners of both sexes. The presence of adults beyond the mother is important for the development of social skills, especially for young horses, because adults may serve as role models. Therefore, it seems that young horses would benefit most from being kept in groups with different age-sex classes for as long as possible, instead of the common practice of weaning foals before 1-year old and keeping them in same-age groups.

However, our findings show that it is generally difficult to predict whether horses will form strong affiliative relationships based on individual factors such as those assessed in this review (e.g. age, gender, dominance, kinship) because these factors were not consistently related to affiliative relationships across different horse populations. When decisions have to be made on which horses will be grouped together, it may then be more useful for horse keepers to monitor affiliative relationships between horses than trying to predict these relationships on the basis of individual factors. Observing social behaviour will allow them to make the necessary adjustments in group composition, housing conditions and management procedures, so that welfare is improved. This monitoring is especially important after introduction or removal of horses and after the birth of foals to assess the effects on affiliative relationships and prevent possible cases of increased aggression. This review presents some behavioural measures that may be used by horse keepers for this purpose.

\section{Introduction and removal of horses from groups}

Because horses develop strong and stable affiliative relationships which affect their welfare, changes in group composition due to introduction and removal of horses should be avoided as much as possible. When animals moved to new groups where most other horses were unfamiliar to them, familiarity was an important factor related to the development of affiliative relationships. Therefore, when a horse is to be transferred to a new group, choosing a group with at least one familiar horse should be preferred, if one is available.

\section{GAPS IN KNOWLEDGE AND AVENUES FOR FUTURE RESEARCH}

Considering the findings of previous studies, we identified areas of research which could be addressed 
in more detail in order to gain a more complete understanding of affiliative relationships among horses. Here we present themes which deserve further investigation and suggest improvements considering methodological issues.

Differences in personality, life history, social competence and social learning may cause interindividual variation in the way each horse expresses an affiliative relationship. For example, as mentioned before, some horses were never observed performing mutual grooming but expressed other types of affiliative behaviour. Therefore, we believe it is important to apply statistical tests that take individual variation into account and to use multiple behavioural measures to assess affiliative relationships. We recommend the use of several types of affiliative interactions (e.g. approach, follow, friendly contacts, mutual grooming) and proximity measures (e.g. associates, nearest neighbours) and the assessment of correlations between these measures. For the study of proximity relationships, biologically meaningful information can best be obtained by evaluating which individuals are within the personal space (van Dierendonck et al. 2004) because this is the area immediately around the horse in which only close companions are tolerated (for review see Mills and Nankervis 1999). Proximity measures could be more relevant if they take into account a horse's personal space as well as the enclosure or pasture area weighted by the number of horses.

The terminology for describing affiliative relationships could be made more objective by using descriptive terms. For example, some authors used the term "preferred partners", which suggests that affiliative relationships were based on a cognitive ability to make a choice based on preference. This cognitive feature was not tested in observational studies. In addition, there may be social constraints that prevent horses from associating with certain group members thereby imposing limits on their choices. Therefore, "most common partners" or other descriptive terms would be more adequate.

Although affiliative relationships are commonly assessed through a variety of behavioural measures, social skills have not been objectively defined and measured in horses. More study is also needed to understand how the development of these skills is affected by maternal investment, age at weaning, group members (e.g. peer number, age and gender) and social play. Future studies could also address the impact of social skills on reproductive success later in life.

The underlying motivations and functions of interference and reconciliation behaviours among horses and their role in affiliative relationships could be studied in greater detail. Regarding interference behaviours, it is important to analyze the type of behaviour that was used to interfere (affiliative or agonistic), the identity of the target horse and the immediate effect of interference (e.g. separation, replacement). Regarding reconciliation, we believe that the type and intensity of agonistic interactions and the kind of affiliative interactions exchanged between the horses after the agonistic interaction should be taken into account. Moreover, when studying interference and reconciliation, social interactions may be directed to group members that are interacting with one another merely by chance. For example, horses that intend to interfere in interactions of group members may be expected to pay attention to those social interactions prior to intervening on them. Therefore, attention could also be measured, through gazing, ear turning, head and neck lifting and orientation of the body towards the target.

Cooperative behaviours and their association with affiliative relationships have not been investigated in horses. Cooperation in horses has been given little attention, except among males in bands with multiple stallions, as referred earlier. Heitor et al. (2011) reported that sexual interference behaviours in Sorraia horses seemed to be related to mare protection, but more studies are needed to understand whether these behaviours could be explained by cooperation. It could also be tested whether interference in agonistic interactions of other mares or their foals can be explained through cooperative hypotheses. Vigilance behaviours and tolerance at feeding sites could also be investigated as subtle forms of cooperation.

\section{CONCLUSIONS}

Horses develop strong and stable affiliative 
relationships that have been favoured by natural selection through increased survival and reproductive success. Affiliative relationships are associated with a variety of individual and social factors, but the relative importance of these factors shows large variation between horse populations. Age similarity, mare reproductive state and social environment were some of the most relevant factors associated with affiliative relationships. We argue that horse husbandry practices should be supported by the body of scientific knowledge that has been gathered to date on horses' social needs and affiliative behaviour. Domestic horses should be provided with conditions to express their natural affiliative behaviours and develop social skills. Regarding fundamental research, we suggest that promising areas for future study include social skills, interference, reconciliation and cooperative behaviours.

\section{ETHICAL STATEMENT}

The work described in this article did not require approval by EU Directive 2010/63/EU for animal experiments.

\section{CONFLICT OF INTEREST STATEMENT}

We declare to have no conflict of interest.

\section{REFERENCES}

Andersen, I.L., Nævdal, E., Bøe, K.E., and Bakken, M. 2006. The significance of theories in behavioural ecology for solving problems in applied ethology Possibilities and limitations. Applied Animal Behaviour Science 97: 85-104. doi: 10.1016/j.applanim.2005.11.020

Araba, B.D., and Crowell-Davis, S.L. 1994. Dominance relationships and aggression of foals (Equus caballus). Applied Animal Behaviour Science 41: 1-25. doi: 10.1016/0168-1591(94)90048-5

Arnold, G.W., and Grassia, A. 1982. Ethogram of agonistic behaviour for thoroughbred horses. Applied Animal Ethology 8: 5-25. doi: 10.1016/03043762(82)90129-8
Bekoff, M. and Allen, C. 1998. Intentional communication and social play: how and why animals negotiate and agree to play. In Animal Play: Evolutionary, Comparative, and Ecological Perspectives, 97114, ed. M. Bekoff and J.A. Byers. Cambridge and New York: Cambridge University Press. doi: 10.1017/СBO9780511608575.006

Berger, J. 1983. Induced abortion and social factors in wild horses. Nature 303: 59-61. doi: 10.1038/303059a0

Berger, J. 1986. Wild Horses of the Great Basin: Social Competition and Population Size. Chicago: University of Chicago Press.

Bourjade, M., Moulinot, M., Henry, S., Richard-Yris, M.A., and Hausberger, M. 2008. Could adults be used to improve social skills of young horses, Equus caballus? Developmental Psychobiology 50: 408-417. doi: 10.1002/dev.20301

Bourjade, M., es Roches, A.B., and Hausberger, M. 2009. Adult-young ratio, a major factor regulating social behaviour of young: a horse study. PLOS ONE 4, e4888. doi: 10.1371/journal.pone.0004888

Broom, D.M. 1986. Indicators of poor welfare. British Veterinary Journal 142: 524-526. doi: 10.1016/00071935(86)90109-0

Bouskila, A., Lourie, E., Sommer, S., de Vries, H., Hermans, Z.M., and van Dierendonck, M. 2015. Similarity in sex and reproductive state, but not relatedness, influence the strength of association in the social network of feral horses in the Blauwe Kamer Nature Reserve. Israel Journal of Ecology \& Evolution 61: 106-113. doi: 10.1080/15659801.2016.1149921

Cameron, E.Z., Setsaas, T.H., and Linklater, W.L. 2009. Social bonds between unrelated females increase reproductive success in feral horses. Proceedings of the National Academy of Sciences of the United States of America 106: 13850-13853. doi: 10.1073/pnas.0900639106

Clutton-Brock, T.H., Greenwood, P.J., and Powell, R.P. 1976. Ranks and relationships in Highland ponies and Highland cows. Zeitschrift für Tierpsychologie 41 : 202216. doi: 10.1111/j.1439-0310.1976.tb00477.x 
Cozzi, A., Sighieri, C., Gazzano, A., Nicol, C. J., and Baragli, P. 2010. Post-conflict friendly reunion in a permanent group of horses (Equus caballus). Behavioural Processes 85: 185-190. doi: 10.1016/j.beproc.2010.07.007

Crowell-Davis, S.L., Houpt, K.A., and Carini, C.M. 1986. Mutual grooming and nearest-neighbor relationships among foals of Equus caballus. Applied Animal Behaviour Science 15: 113-123. doi: 10.1016/01681591(86)90057-2

Duncan, P. 1980. Time-budgets of Camargue horses: II. Time-budgets of adult horses and weaned sub-adults. Behaviour 72: 26-49. doi: 10.1163/156853980X00023

Duncan, P., Feh, C., Gleize, J.C., Malkas, P., and Scott, A.M. 1984. Reduction of inbreeding in a natural herd of horses. Animal Behaviour 32, 520-527. doi: 10.1016/S0003-3472(84)80290-0

Estep, D.Q., Crowell-Davis, S.L., Earl-Costello, S.A., and Beatey, S.A. 1993. Changes in the social behaviour of drafthorse (Equus caballus) mares coincident with foaling. Applied Animal Behaviour Science 35: 199-213. doi: 10.1016/0168-1591(93)90137-E

Feh, C., and de Mazières, J. 1993. Grooming at a preferred site reduces heart rate in horses. Animal Behaviour 46: 1191-1194. doi: 10.1006/anbe.1993.1309

Feh, C. 1999. Alliances and reproductive success in Camargue stallions. Animal Behaviour 57: 705-713. doi: 10.1006/anbe.1998.1009

Feist, J.D., and McCullough, D.R. 1976. Behavior patterns and communication in feral horses. Zeitschrift für Tierpsychologie 41: 337-371. doi: 10.1111/j.14390310.1976.tb00947.x

Gilbert-Norton, L., Jule, K., Richards, G., and Goto, K. 2004. Social structure of pony (Equus caballus) mares in an all female herd on Lundy: analysis of dominance relationship and preferred associate. Lundy Field Society - Annual Report 54: 71-88.
Granquist, S.M., Thórhallsdóttir, A.G., and Sigurjónsdóttir, H. 2012. The effect of stallions on social interactions in domestic and semi feral harems. Applied Animal Behaviour Science 141: 49-56. doi: 10.1016/j.applanim.2012.07.001

Hartmann, E., Søndergaard, E., and Keeling, L.J. 2012. Keeping horses in groups: A review. Applied Animal Behaviour Science 136: 77-87. doi: 10.1016/j.applanim.2011.10.004

Heitor, F., Oom, M.M., and Vicente, L. 2006a. Social relationships in a herd of Sorraia horses: Part I. Correlates of social dominance and contexts of aggression. Behavioural Processes 73: 170-177. doi: 10.1016/j.beproc.2006.05.004

Heitor, F., Oom, M.M., and Vicente, L. 2006b. Social relationships in a herd of Sorraia horses: Part II. Factors affecting affiliative relationships and sexual behaviours. Behavioural Processes 73: 231-239. doi: 10.1016/j.beproc.2006.05.005

Heitor, F., and Vicente, L. 2008. Maternal care and foal social relationships in a herd of Sorraia horses: Influence of maternal rank and experience. Applied Animal Behaviour Science 113: 189-205. doi: 10.1016/j.applanim.2007.11.005

Heitor, F., and Vicente, L. 2010. Affiliative relationships among Sorraia mares: influence of age, dominance, kinship and reproductive state. Journal of Ethology 28: 133-140. doi: 10.1007/s10164-009-0165-9

Heitor, F., Emídio, S. and Vicente, L. 2011. Sexual interference behaviour by Sorraia mares (Equus caballus). In Horses: Biology, Domestication, and Human Interactions, 65-84, ed. J.E. Leffhalm. New York: Nova Science Publishers.

Hoffmann, R. 1985. On the development of social behaviour in immature males of a feral horse population (Equus przewalskii f. caballus). Zeitschrift für Säugetierkunde 50: 302-314. 
Houpt, K.A., Law, K., and Martinisi, V. 1978. Dominance hierarchies in domestic horses. Applied Animal Ethology 4: 273-283. doi: 10.1016/03043762(78)90117-7

Houpt, K.A., and Keiper, R. 1982. The position of the stallion in the equine dominance hierarchy of feral and domestic ponies. Journal of Animal Science 54: 945-950. doi: $10.2527 /$ jas1982.545945x

Jansen, T., Forster, P., Levine, M.A., Oelke, H., Hurles, M., Renfrew, C., Weber, J., and Olek, K. 2002. Mitochondrial DNA and the origins of the domestic horse. Proceedings of the National Academy of Sciences of the United States of America 99: 10905-10910. doi: 10.1073/pnas.152330099

Kaseda, Y., Khalil, A.M., and Ogawa, H. 1995. Harem stability and reproductive success of Misaki feral mares. Equine Veterinary Journal 27, 368-372. doi: 10.1111/j.2042-3306.1995.tb04072.x

Keiper, R.R. 1986. Social structure. Veterinary Clinics of North America: Equine Practice 2: 465-484. doi: 10.1016/S0749-0739(17)30701-0

Keiper, R.R. 1988. Social interactions of the Przewalski horse (Equus przewalskii Poliakov, 1881) herd at the Munich Zoo. Applied Animal Behaviour Science 21: 89-97. doi: 10.1016/0168-1591(88)90102-5

Khalil, A.M., and Kaseda, Y. 1998. Early experience affects developmental behaviour and timing of harem formation in Misaki horses. Applied Animal Behaviour Science 59: 253-263. doi: 10.1016/S0168-1591(98)00111-7

Kimura, R. 1998. Mutual grooming and preferred associate relationships in a band of free-ranging horses. Applied Animal Behaviour Science 59: 265-276. doi: 10.1016/S0168-1591(97)00129-9

Klimov, V.V. 1988. Spatial-ethological organization of the herd of Przewalski horses (Equus przewalskii) in Askania-Nova. Applied Animal Behaviour Science 21: 99115. doi: 10.1016/0168-1591(88)90103-7
Klingel, H. 1975. Social organization and reproduction in equids. Journal of Reproduction and Fertility 23 (Suppl.): 7-11.

Kolter, L., and Zimmermann, W. 1988. Social behaviour of Przewalski horses (Equus p. przewalskii) in the Cologne Zoo and its consequences for management and housing. Applied Animal Behaviour Science 21: 117145. doi: 10.1016/0168-1591(88)90104-9

Krueger, K., Flauger, B., Farmer, K., and Hemelrijk, C. 2014. Movement initiation in groups of feral horses. Behavioural Processes 103, 91-101. doi: 10.1016/j.beproc.2013.10.007

Krueger, K., Schneider, G., Flauger, B., and Heinze, J. 2015. Context-dependent third-party intervention in agonistic encounters of male Przewalski horses. Behavioural Processes 121: 54-62. doi: 10.1016/j.beproc.2015.10.009

Linklater, W.L. 2000. Adaptive explanation in socioecology: Lessons from the Equidae. Biological Reviews 75, 1-20. doi: 10.1111/j.1469-185X.1999.tb00039.x

Linklater, W.L., Cameron, E.Z. 2000. Tests for cooperative behaviour between stallions. Animal Behaviour 60: 731-743. doi: 10.1006/anbe.2000.1525

Linklater, W.L., Cameron, E.Z., Minot, E.O., and Stafford, K.J. 1999. Stallion harassment and the mating system of horses. Animal Behaviour 58: 295-306. doi: 10.1006/anbe.1999.1155

McDonnell, S.M., and Haviland, J.C.S. 1995. Agonistic ethogram of the equid bachelor band. Applied Animal Behaviour Science 43: 147-188. doi: 10.1016/01681591(94)00550-X

McDonnell, S.M., and Poulin, A. 2002. Equid play ethogram. Applied Animal Behaviour Science 78: 263-290. doi: 10.1016/S0168-1591(02)00112-0

Mills, D.S. and Nankervis, K.J. 1999. Equine Behaviour: Principles and Practice. Oxford: Blackwell Science Publications. 
Monard, A.M., and Duncan, P. 1996. Consequences of natal dispersal in female horses. Animal Behaviour 52: 565-579. doi: 10.1006/anbe.1996.0198

Monard, A.M., Duncan, P., and Boy, V. 1996. The proximate mechanisms of natal dispersal in female horses. Behaviour 133: 1095-1124. doi: 10.1163/156853996X00611

Pavelka, M.S.M. 1991. Sociability in old female Japanese monkeys: human versus nonhuman primate aging. American Anthropologist 93: 588-598. doi: 10.1525/aa.1991.93.3.02a00030

Price, E.O. 1999. Behavioral development in animals undergoing domestication. Applied Animal Behaviour Science 65, 245-271. doi: 10.1016/S0168-1591(99)00087-8

Redgate, S.E. and Davidson H.P.B. 2007. The effects on behaviour of the presence or absence of a familiar horse during feeding. In Horse Behaviour and Welfare, 65-69, ed. M. Hausberger, E. Søndergaard and W. MartinRosset. Netherlands: Wageningen Academic Publishers. doi: 10.3920/978-90-8686-614-4

Rho, J.R., Srygley, R.B., and Choe, J.C. 2007. Sex preferences in Jeju pony foals (Equus caballus) for mutual grooming and play-fighting behaviors. Zoological Science 24: 769-773. doi: 10.2108/zsj.24.769

Rutberg, A.T., and Greenberg, S.A. 1990. Dominance, aggression frequencies and modes of aggressive competition in feral pony mares. Animal Behaviour 40: 322-331. doi: 10.1016/S0003-3472(05)80927-3

Salter, R.E., and Hudson, R.J. 1982. Social organization of feral horses in western Canada. Applied Animal Ethology 8: 207-223. doi: 10.1016/0304-3762(82)90205-X

Schneider, G., and Krueger, K. 2012. Third-party interventions keep social partners from exchanging affiliative interactions with others. Animal Behaviour 83: 377-387. doi: 10.1016/j.anbehav.2011.11.007
Sigurjónsdóttir, H., van Dierendonck, M.C., Snorrason, S., and Thórhallsdóttir, A.G. 2003. Social relationships in a group of horses without a mature stallion. Behaviour 140: 783-804. doi: $10.1163 / 156853903322370670$

Søndergaard, E. and Christensen, J.W. 2007. The effects of social environment on the behaviour of young horses. In Horse Behaviour and Welfare, 71-77, ed. M. Hausberger, E. Søndergaard and W. Martin-Rosset. Netherlands: Wageningen Academic Publishers. doi: 10.3920/978-90-8686-614-4

Tyler, S. 1972. The behaviour and social organization of the New Forest ponies. Animal Behaviour 5: 85-196. doi: 10.1016/0003-3472(72)90003-6

van Dierendonck, M.C., de Vries, H., and Schilder, M.B.H. 1995. An analysis of dominance, its behavioural parameters and possible determinants in a herd of Icelandic horses in captivity. Netherlands Journal of Zoology 45: 362-385.

van Dierendonck, M.C., Sigurjónsdóttir, H., Colenbrander, B., and Thórhallsdóttir, A. G. 2004. Differences in social behaviour between late pregnant, post-partum and barren mares in a herd of Icelandic horses. Applied Animal Behaviour Science 89: 283-297. doi: 10.1163/156854295X00366

van Dierendonck, M.C. 2006. The importance of social relationships in horses. Ph.D. thesis, Utrecht University, Netherlands.

van Dierendonck, M.C., de Vries, H., Schilder, M.B.H., Colenbrander, B., Thorhallsdóttir, A.G., and Sigurjónsdóttir, H. 2009. Interventions in social behaviour in a herd of mares and geldings. Applied Animal Behaviour Science 116: 67-73. doi: 10.1016/j.applanim.2008.07.003

van Dierendonck, M.C., and Spruijt, B.M. 2012. Coping in groups of domestic horses - Review from a social and neurobiological perspective. Applied Animal Behaviour Science 138: 194-202. doi: 10.1016/j.applanim.2012.02.007 
Veenema, H.C., Spruijt, B.M., Gispen, W.H., and van Hooff, J.A. 1997. Aging, dominance history, and social behavior in Java-monkeys (Macaca fascicularis). Neurobiology of Aging 5: 509-515. doi: 10.1016/S01974580(97)00107-3

Visser, E., Ellis, A., and van Reenen, C. 2008. The effect of two different housing conditions on the welfare of young horses stabled for the first time. Applied Animal Behaviour Science 114: 521-533. doi: 10.1016/j.applanim.2008.03.003

Waring, G.H. 1983. Horse Behavior: The Behavioral Traits and Adaptations of Domestic and Wild Horses, Including Ponies. New Jersey: Noyes Publications.
Weeks, J.W., Crowell-Davis, S.L., Caudle, A.B., and Heusner, G.L. 2000. Aggression and social spacing in light horse (Equus caballus) mares and foals. Applied Animal Behaviour Science 68: 319-337. doi: 10.1016/S01681591(99)00126-4

Wells, S.M., and von Goldschmidt-Rothschild, B. 1979. Social behaviour and relationships in a herd of Camargue horses. Zeitschrift für Tierpsychologie 49: 363380. doi: 10.1111/j.1439-0310.1979.tb00299.x

Zharkikh, T.L., and Andersen, L. 2009. Behaviour of bachelor males of the Przewalski Horse (Equus ferus przewalskii) at the Reserve Askania Nova. Der Zoologische Garten 78: 282-299. doi: 10.1016/j.zoolgart.2009.10.005

\section{@creative}

This paper has been published by

Pet Behaviour Science

under a Creative Commons license 4.0 Non-comercial - Share Alike - Attribution

As an open access journal, it is free of charges for both authors and readers

www.petbehaviourscience.org 